\title{
DETERMINAÇÃO DA ATIVIDADE ANTIBACTERIANA E ANTIOXIDANTE DO ÓLEO ESSENCIAL DAS FOLHAS DE Cymbopogon flexuosus contra Listeria monocytogenes e Pseudomonas aeruginosa
}

\author{
K. A. DALLA COSTA ${ }^{1}$, M. FERENZ², S. M. da SILVEIRA², R. MOURA², A. F. MILLEZI² \\ ${ }^{1}$ Universidade Regional Integrada do Alto Uruguai e das Missões \\ ${ }^{2}$ Instituto Federal Catarinense \\ E-mail para contato: karinedallacosta@ hotmail.com
}

\begin{abstract}
RESUMO - O objetivo deste estudo foi determinar a atividade antimicrobiana e antioxidante do óleo essencial (OE) obtido das folhas de Cymbopogon flexuosus (capimlimão da Índia Oriental). A atividade antimicrobiana foi desenvolvida contra Pseudomonas aeruginosa ATCC 27853 e Listeria monocytogenes ATCC 19117 a fim de iniciar estudos para o desenvolvimento de um detergente-sanificante. A eficiência do OE foi detectada pelo método da Concentração Mínima Inibitória (CMI) e Concentração Mínima Bactericida (CMB). Todos os ensaios foram realizados em triplicata e em três repetições. A atividade antioxidante do $\mathrm{OE}$ foi avaliada pelo consumo do radical livre DPPH comparado com os antioxidantes sintéticos BHT e ácido gálico. Foram testadas oito concentrações do $\mathrm{OE}$, partindo de 3,9 à $1000 \mu \mathrm{L} \mathrm{mL}^{-1}$. Os resultados apontaram ação contra L. monocytogenes, com valores de CMI e CMB de $3,9 \mu \mathrm{L} \mathrm{mL}^{-1}$ apresentando atividade antimicrobiana satisfatória, devido esta ser a menor concentração testada. Nenhuma das concentrações testadas foi eficiente para inibir P. aeruginosa. Avaliando o combate a radicais livres verificou-se excelente eficiência em todas as concentrações do OE analisadas, demostrando grande potencial antioxidante. Esses resultados refletem eficiente atividade antioxidante e antimicrobiana do OE de Cymbopogon flexuosus contra L. monocytogenes indicando o possível uso na formulação de alimentos e/ou solução detergente-sanificante.
\end{abstract}

Palavras-chave: antimicrobiano natural, antioxidante natural, bactérias patogênicas, capim-limão.

DOI: $10.5965 / 24473650312017003$

\section{INTRODUÇÃO}

Microrganismos presentes nos alimentos podem causar alterações químicas prejudiciais, além de representarem risco à saúde da população (FRANCO, LANDGRAF, 2006). Embora existam inúmeros antimicrobianos sendo desenvolvidos no mercado nos últimos anos, observa-se em 
contrapartida a crescente resistência microbiana a estas substâncias (SILVA, 2010).

As alterações nos alimentos também podem estar relacionadas com a rancidez oxidativa, principal responsável por alterações indesejáveis de cor, sabor, aroma e consistência do alimento. A oxidação lipídica envolve complexas reações químicas, levando à formação de radicais livres que em excesso podem causar um efeito tóxico ao organismo. Uma substancia antioxidante pode minimizar este processo (RIBEIRO, SERAVALLI, 2007).

Em função de alguns antioxidantes e antimicrobianos sintéticos serem alvos de questionamentos quanto à inocuidade, demostrando a possibilidade de desencadear alguma complicação à saúde do consumidor (WURTZEN, 1990) existem buscas crescentes por compostos antioxidantes e antimicrobianos naturais, principalmente os provenientes de espécie vegetais (Sousa et al., 2007).

Desta maneira, plantas ricas em óleos essenciais podem ser utilizadas nos alimentos a fim de conferir sabor, aroma e pungência, destacando-se ainda propriedades antioxidantes, antimicrobianas e nutricionais. Além dos efeitos diretos, a utilização dessas plantas pode levar a efeitos secundários mais complexos, como a prevenção da deterioração dos alimentos (PETER, 2004).

O objetivo deste estudo foi determinar a atividade antimicrobiana e antioxidante do OE obtido das folhas de Cymbopogon flexuosus (capim-limão da Índia Oriental).

\section{MATERIAL E MÉTODOS}

As análises foram realizadas no laboratório de Microbiologia de Alimentos e Bromatologia localizado no Instituto Federal Catarinense campus Concórdia, SC.

A atividade antimicrobiana foi desenvolvida contra Pseudomonas aeruginosa ATCC 27853 e Listeria monocytogenes ATCC 19117 a fim de iniciar estudos para o desenvolvimento de um detergente-sanificante. A eficiência do OE foi detectada pelo método da Concentração Mínima Inibitória (CMI) e Concentração Mínima Bactericida (CMB) descrito por NCCLS/CLSI (2003), com adaptações. Todos os ensaios foram realizados em triplicata e em três repetições, os resultados foram expressos em $\mu \mathrm{L} \mathrm{mL}{ }^{-1}$.

Foram adicionados $100 \mu \mathrm{L}$ do óleo puro e então diluídos sucessivamente nas concentrações de $50 \mathrm{mg} \mathrm{mL}^{-1}$ a $0,39 \mathrm{mg} \mathrm{mL}^{-1}$, em caldo Brain Heart Infusion (BHI) com 0,5\% de tween 80.

Posteriormente adicionou-se $90 \mu \mathrm{L}$ do meio de cultura BHI e por fim $10 \mu \mathrm{L}$ da suspensão bacteriana ajustada a uma concentração de aproximadamente $10^{7} \mathrm{UFC} \mathrm{mL}^{-1}$.

Em cada linha, foram mantidos controles de esterilidade e controles de crescimento. As placas foram incubadas a $36{ }^{\circ} \mathrm{C}$ por $18 \mathrm{~h}-24 \mathrm{~h}$ sendo que o crescimento microbiano foi detectado visualmente pela adição de $20 \mu \mathrm{L}$ de solução aquosa de cloreto de trifeniltetrazólio (TTC) a $0,5 \%$ $(\mathrm{m} / \mathrm{v})$, com incubação adicional de 1 hora, à mesma temperatura.

A concentração mínima bactericida $(\mathrm{CMB})$ dos extratos foi determinada a partir das placas utilizadas para a determinação da CMI, através de metodologia descrita por Silveira (2012). De cada poço onde não ocorreu crescimento microbiano, foram transferidos $10 \mu \mathrm{L}$ para placas de Ágar Triptona de Soja (TSA). As placas foram incubadas a $36^{\circ} \mathrm{C}$ por $24 \mathrm{~h}$ e o crescimento de colônias foi verificado. As análises foram realizadas em triplicata e os resultados expressos em $\mathrm{mg} \mathrm{mL}^{-1}$.

Tanto a CMI quanto a CMB foi definida como a menor concentração do OE capim limão que impediu totalmente o crescimento microbiano nas placas.

A atividade antioxidante do OE foi avaliada pelo consumo do radical livre DPPH (2,2-difenil-1- 
picrilhidrazil), utilizando os antioxidantes sintéticos BHT e ácido gálico como controle positivo, metodologia esta adaptada de Brand-Williams et al. (1995).

Foram testadas oito concentrações do $\mathrm{OE}$, partindo de 3,9 à $1000 \mu \mathrm{L} \mathrm{mL}^{-1}$. Posteriormente da realização da diluição do $\mathrm{OE}$, iniciou-se o teste da potencialidade antioxidante de cada concentração: foram adicionados $20 \mu \mathrm{L}$ de cada concentração do OE e $180 \mu \mathrm{L}$ de DPPH, totalizando $200 \mu \mathrm{L}$ em cada poço da placa de 96 poços. A mistura foi incubada a $25^{\circ} \mathrm{C}$ por 30 minutos em ausência de luz. $\mathrm{O}$ decréscimo da absorbância de cada solução foi medido a $490 \mathrm{~nm}$. A capacidade de sequestro de radical DPPH foi calculada de acordo com a equação: Capacidade de sequestro de radical DPPH (\%) $=[(\mathrm{A} 0-\mathrm{A} 1) / \mathrm{A} 0] 100$, onde A0 é a absorbância do controle e A1 é a absorbância na presença do óleo. A análise foi realizada em triplicata e o valor apresentado como a média ( \pm desvio padrão).

\section{RESULTADOS E DISCUSSÕES}

Os resultados apontaram ação contra L. monocytogenes, com valores de CMI e CMB de 3,9 $\mu \mathrm{L}$ $\mathrm{mL}^{-1}$ apresentando atividade antimicrobiana satisfatória (Figura 1), devido esta ser a menor concentração testada. Nenhuma das concentrações testadas foi eficiente para inibir P. aeruginosa, então foi realizada a contagem das células da maior concentração $\left(500 \mu \mathrm{L} \mathrm{mL}^{-1}\right)$ em comparação com o controle positivo, no qual se obteve redução de células viáveis de 1,6 CFU Log $10 \mathrm{~mL}^{-1}$.

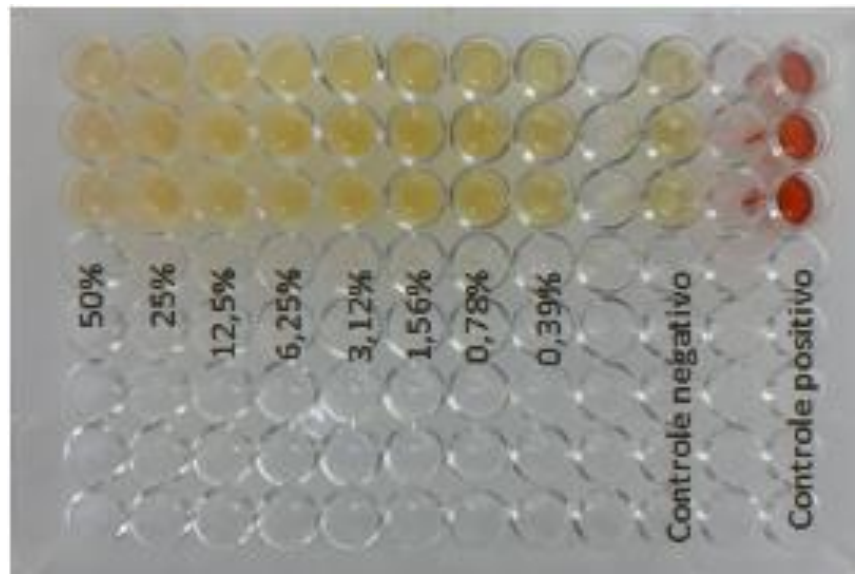

Figura 1 - Resultados Concentração mínima inibitória de L. monocytogenes.

Essa ação antimicrobiana eficiente para L. monocytegenes pode ser devido a hidrofobicidade do $\mathrm{OE}$, pois são facilmente difundidos pela parede celular dos microrganismos e causam danos à membrana, principalmente no que diz respeito à fluidez e permeabilidade (MILLEZI et al., 2012). Portanto, os óleos essenciais, inclusive o de capim limão, têm maior atividade frente a bactérias Gram-positivas. As Gram-negativas são mais resistentes devido à maior complexidade da sua membrana plasmática, que atua como uma barreira à difusão dos componentes hidrofóbicos dos óleos essenciais (NAIK et al., 2010).

Para avaliar a atividade antioxidante por meio da captura de radicais livres já formados foi utilizado o método de habilidade de sequestro do radical DPPH $\bullet$. Na Figura 2 pode-se observar o comportamento da atividade antioxidante em relação as nove concentrações testadas do óleo 
essencial.

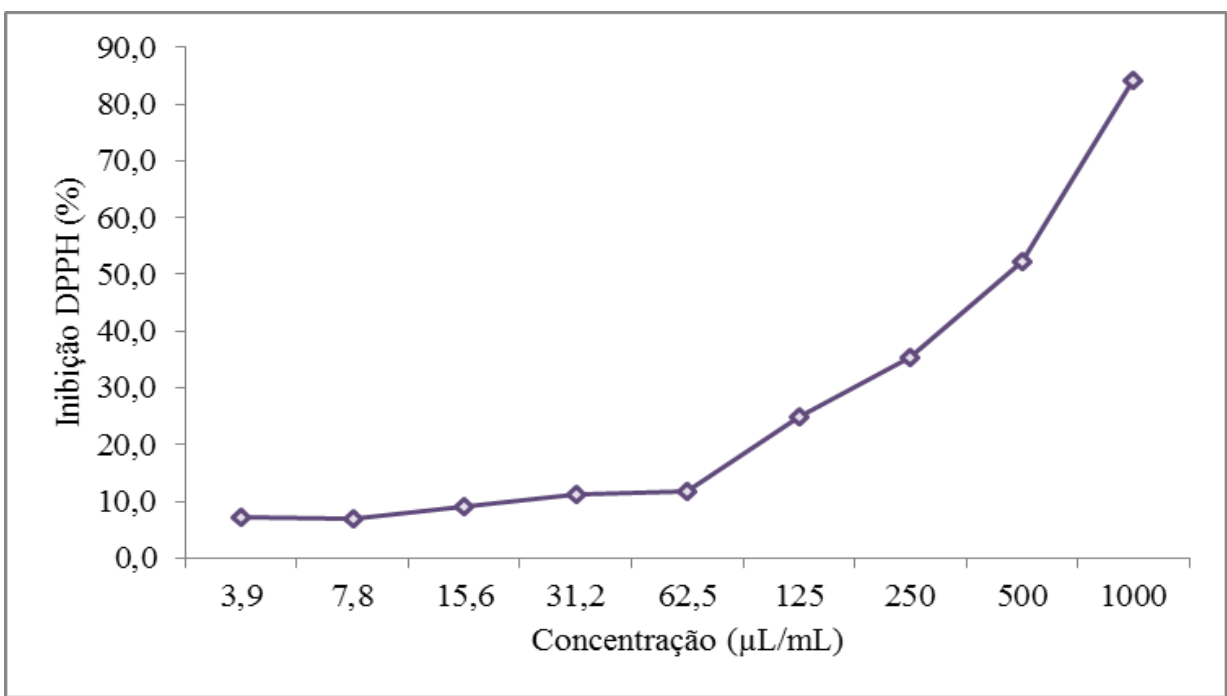

Figura 2 - Porcentagem de atividade antioxidante do óleo essencial estudado.

Nas Figuras 3 e 4 está demonstrando o comportamento da concentração dos antioxidantes sintéticos BHT e Ácido gálico, respectivamente em cada diluição do OE. Observa-se que em todas as concentrações a habilidade de reduzir o DPPH das substâncias sintéticas foi muito superior quando comparado ao óleo capim-limão do estudo. Além disso, verificou-se uma elevação da concentração dos antioxidantes sintéticos nas concentrações menores do OE quando comparada aos antioxidantes padrões, este desempenho deve ser estudado futuramente.

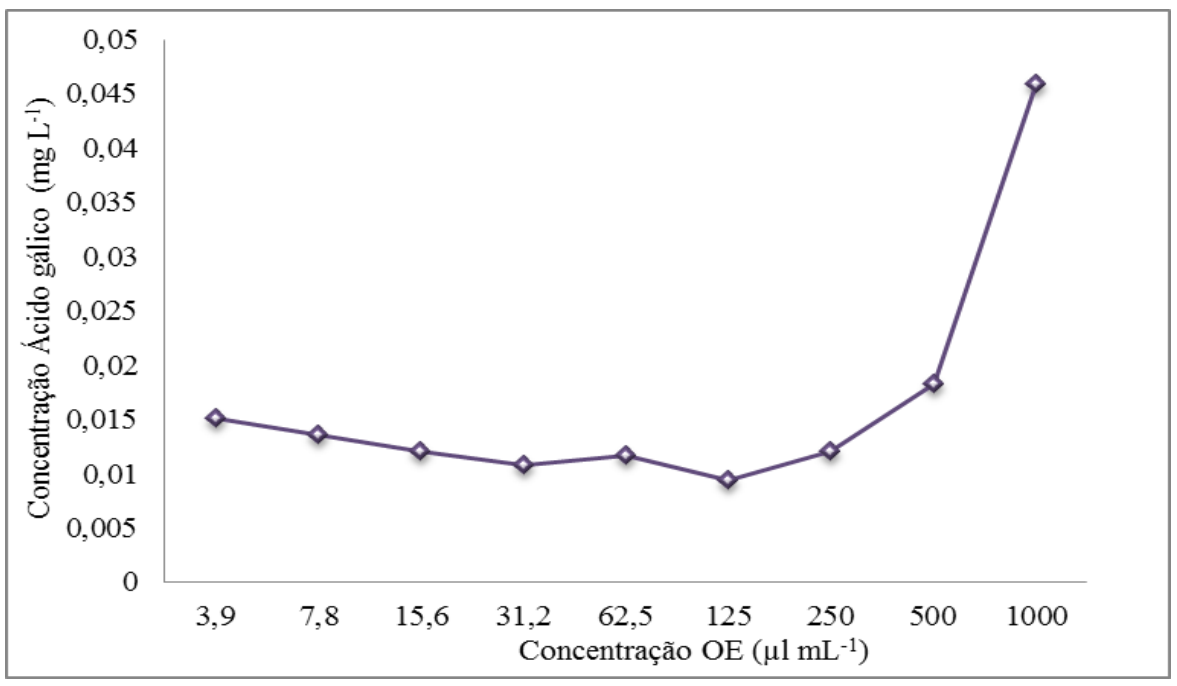

Figura 3 - Concentração do ácido gálico em cada diluição do óleo Capim limão. 


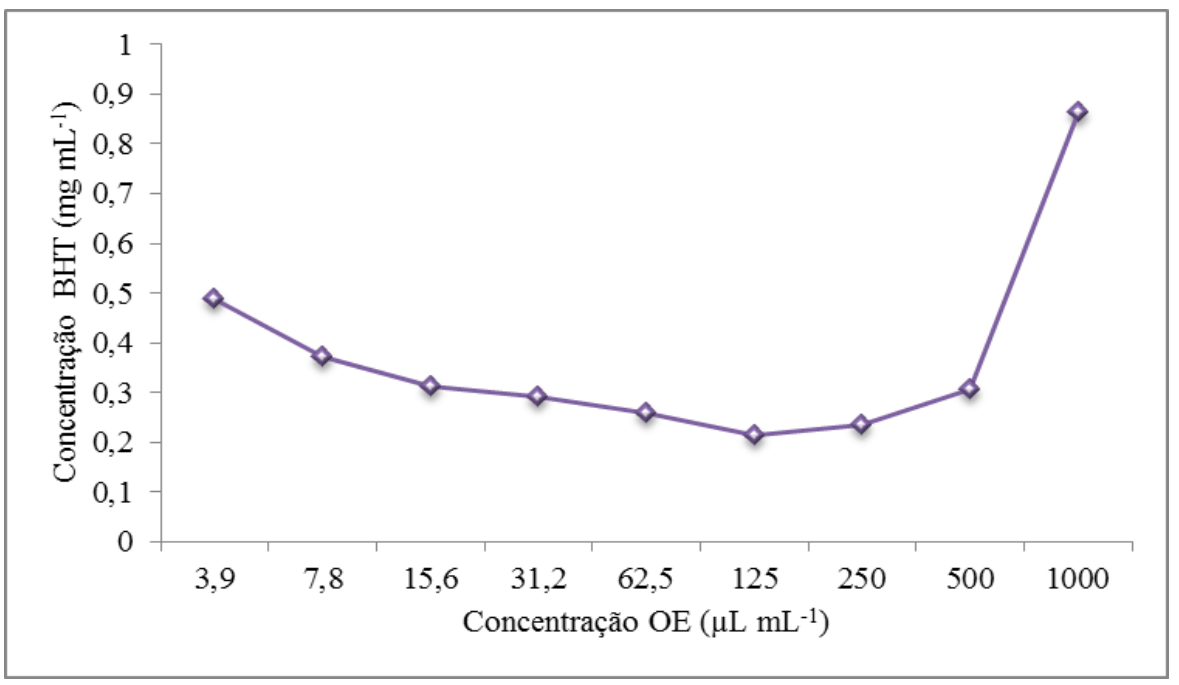

Figura 4 - Concentração do BHT em cada diluição do óleo Capim limão.

O potencial de sequestro do radical $\mathrm{DPPH} \bullet$ é baseado na redução deste radical em solução metanólica pelo antioxidante doador de hidrogênio $(\mathrm{AH})$ ou por um radical $(\mathrm{R} \bullet)$, como na reação: $\mathrm{DPPH} \bullet+\mathrm{AH}$ DPPH-H + A • ou DPPH•+ R・ DPPH. Com o DPPH restante desta reação é calculado o IC50 (quantidade suficiente para inibir 50\% do DPPH) que corresponde à atividade inversa do potencial de captura do radical, ou seja, quanto menor o IC50 melhor é o potencial antioxidante da amostra testada (BRAND-WILLIAMS et al., 1995).

Neste estudo, o óleo essencial testado apresentou IC50 de $6,52 \mu \mathrm{L} \mathrm{mL}^{-1} \pm 0,6813$ obtendo melhor atividade antioxidante quando comparado a espécies do mesmo gênero. Selin (2011) observou em seus estudos IC50 de 998,47 $\mathrm{mg} \mathrm{mL}^{-1} \pm 67,65$ para Cymbopogon proximus Stapf, já Scherer e seus colaboradores (2009) verificaram valores de $7,8 \mu \mathrm{L} \mathrm{mL} \mathrm{mL}^{-1} \pm 0,65,743 \mu \mathrm{L} \mathrm{mL} \mathrm{mL}^{-1} \pm 18$ e nenhuma habilidade de redução de DPPH para óleo de cravo (Caryophillus aromaticus L.), citronela (Cymbopogon winterianus) e palmarosa (Cymbopogon martinii), respectivamente.

Percebe-se proximidade entre os valores encontrados de IC50 do óleo deste estudo e o óleo de cravo relatado por Scherer et al. (2009). Segundo Scherer et al. (2009), esta ação antioxidante é provavelmente devido ao elevado teor de eugenol presente na composição do óleo.

\section{CONCLUSÃO}

Esse estudo refletiu potencial antioxidante e atividade antimicrobiana do OE de Cymbopogon flexuosus, exceto a espécie bacteriana $P$. aeruginosa, indicando o possível uso na formulação de alimentos e/ou solução detergente-sanificante. Trabalhos futuros direcionam estudos de ação antimicrobiana e antioxidante de outras substâncias e outros microrganismos de interesse em alimentos bem como a realização de testes em matrizes alimentares e detergentes-sanificantes para comprovar a eficácia. 


\section{AGRADECIMENTOS}

Ao Conselho Nacional de Desenvolvimento Científico e Tecnológico (CNPq) e ao Instituto Federal Catarinense - Campus Concórdia.

\section{REFERENCIAS}

BRAND-WILLIAMS, W.; CUVELIER, M. E. E.; BERSET, C. Use of a free radical method to evaluate antioxidant activity. Food Science and Technology, v. 28, p. 25-30, 1995.

FRANCO, B. D. G. M. E LANDGRAF, M. Microbiologia dos Alimentos. São Paulo: Editora Atheneu, 2006.

MILLEZI, F. M; PEREIRA, M. O.; BATISTA, N. N.; CAMARGOS, N.; AUAD, I.; CARDOSO, M. D. G. E PICCOLI, R. H. Susceptibility of monospecies and dual-species biofilms of Staphylococcus aureus and Escherichia coli to essential oils. Journal of Food Safety, v. 32, p. 351-359, 2012.

NAIK, M.I.; FOMDA, B.A.; JAYKUMAR, E.; BHAT, J.A. Antibacterial activity of lemongrass (Cymbopogon citratus) oil against some selected pathogenic bacterias. Asian Pacific Journal of Tropical Medicine, v. 1, n.1, p. 535-538, 2010.

NCCLS/CLSI. Methods for Dilution Antimicrobial Susceptibility Tests for Bacteria that Grow Aerobically; Approved Standard. NCCLS document M7-A6 [ISBN 1-56238-486-4]. NCCLS, 940 West Valley Road, Suite 1400, Wayne, Pennsylvania 19087-1898 USA, 6 a edição, 2003.

PETER, K. V. Handbook of herbs and spices. Woodhead Publishing Limited, v. 2, 2004.

RIBEIRO, E.P E SERAVALLI, E.A.G. Química de alimentos. Edgard Bllucher, 2a edição, 2007.

SCHERER, R.; WAGNER, R.; DUARTE, M.C.T.; GODOY, H.T.. Composição e atividades antioxidante e antimicrobiana dos óleos essenciais de cravo-da-índia, citronela e palmarosa. Revista Brasileira de Plantas Medicinais, v. 11, n. 4, p. 442-449, 2009.

SELIM, S. A. Chemical composition, antioxidant and antimicrobial activity of the essential oil and methanol extract of the Egyptian lemongrass Cymbopogon proximus Stapf. Grasas Y Aceites, v. 62 (1), p. 55-61, 2011.

SILVA, P. Farmacologia. Guanabara Koogan, $8^{\mathbf{a}}$ edição, 2010.

SILVEIRA, S. M., Avaliação da atividade antimicrobiana e antioxidante de extratos vegetais e óleos essenciais e aplicação do óleo essencial de louro (L. nobilis) como agente conservador natural em embutido cárneo frescal. Tese de doutorado. Universidade Federal de Santa Catarina. Florianópolis, SC, 2012, 215 p. 
SOUSA, C. M. DE M.; SILVA, H. R.; VIEIRA, G. M. J.; AYRES, M. C. C.; COSTA, C. L. S. DA; ARAÚJO, D. S.; CAVAlCANTE, L. C. D.; BARROS, E. D. S.; ARAÚJO, P. B. DE M.; BRANDÃO, M. S.; CHAVES, M. H. Fenóis totais e atividade antioxidante de cinco plantas medicinais. Química Nova, v. 30, n. 2, p. 351-355, 2007.

WURTZEN, G. Shortcomings of current strategy for toxicity testing of food chemicals: antioxidants. Food Chemistry and Toxicology, v. 28, p. 743-745, 1990. 